\title{
Mapping Living Labs in the Landscape of Innovation Methodologies
}

\author{
Esteve Almirall, Melissa Lee, and Jonathan Wareham
}

\author{
"Innovation is not what innovators do but what customers adopt." \\ Michael Schrage \\ Professor and thought leader on innovation
}

\begin{abstract}
A growing interest in living labs as a mechanism for innovation has drawn significant attention to both the different flavours of this methodology and to the organizations that put it into practice. However, little has been done to assess its impact and to compare its contribution to other innovation methodologies. This article aims to cover that gap by summarizing the most common European living labs approaches and positioning them in the landscape of user-contributed innovation methodology. The merits and appropriateness of living labs in these settings are also assessed.
\end{abstract}

\section{Introduction}

When Time magazine (2006; tinyurl.com/39fbyu) selected "the user" as the person of the year for its front page, it was publicly acknowledging the increasing importance of individual user collaboration and involvement in producing content and, ultimately, in driving innovation.

User involvement can take a variety of forms. Some instances position the user as the main creator, in the case of lead users (von Hippel, 1986; tinyurl.com/94oqoek) or open source communities. Others see participants operating as co-creators in practices such as design thinking (Brown, 2008; tinyurl.com/y9ehqt5). On the other end of the spectrum, participatory or user-centered design treats users as passive subjects whose insights are captured and introduced in the innovation process, such as in applied ethnography, usability, human interaction, or market validation exercises.

Living labs are situated in the fertile, middle ground of user involvement. The term "living labs" often refers to both the methodology and the instrument or agency that is created for its practice. Living labs are driven by two main ideas: i) involving users as co-creators on equal grounds with the rest of participants and ii) experimentation in real-world settings. Living labs provide structure and governance to user participation in the innovation process (Almirall and Wareham, 2008; tinyurl.com/8vwtjw2).

Understanding the merits of this methodology is highly relevant, because agents involved in innovation must select the requisite methodologies to appropriately address their respective challenges.

\section{Research Design}

The authors participated in two EU projects and one national project oriented to support living lab activities, with work packages devoted to the collection of methodologies and best practices. The research took the European Network of Living Labs (ENoLL; openliving labs.eu), a large network of organizations in the EU selfdefined as living labs, as the point of departure. An investigation using secondary sources revealed a list of 48 living lab organizations that were considered potential candidates for the study.

Interviews were conducted with 38 senior managers and researchers including the directors of living labs corresponding to 26 different living lab organizations. The authors also actively participated in three living lab projects in the Catalan network and had significant engagement with ENoLL from 2009 to 2012. 


\title{
Mapping Living Labs in the Landscape of Innovation Methodologies
}

\author{
Esteve Almirall, Melissa Lee, and Jonathan Wareham
}

\section{Living Labs Methodologies}

\section{TestBed Botnia}

TestBed Botnia (testplats.com), founded in 2000, originated in the Centre for Distance-Spanning Technology, a research centre in the Luleå University of Technology. TestBed Botnia specializes in mobile services. A sizeable community of 6,500 users from all over Sweden actively participates in TestBed Botnia living labs. Users have collaborated in a wide range of trials, such as mobile queues at banks, traffic updates through SMS, targeted, location-based commercials, and streamed sporting events over the Internet.

Most methods used are qualitative, often focusing on needs-finding, participatory design, and lead-user involvement. FormIT, the most-used living lab methodology in TestBed Botnia, has three states of product/service development: the design of concepts, the design of prototypes, and the design of the final system (Bergvall-Kåreborn et al., 2006; tinyurl.com/9rvwwrr). The methodology evolves in spiral through these three stages (Figure 1).

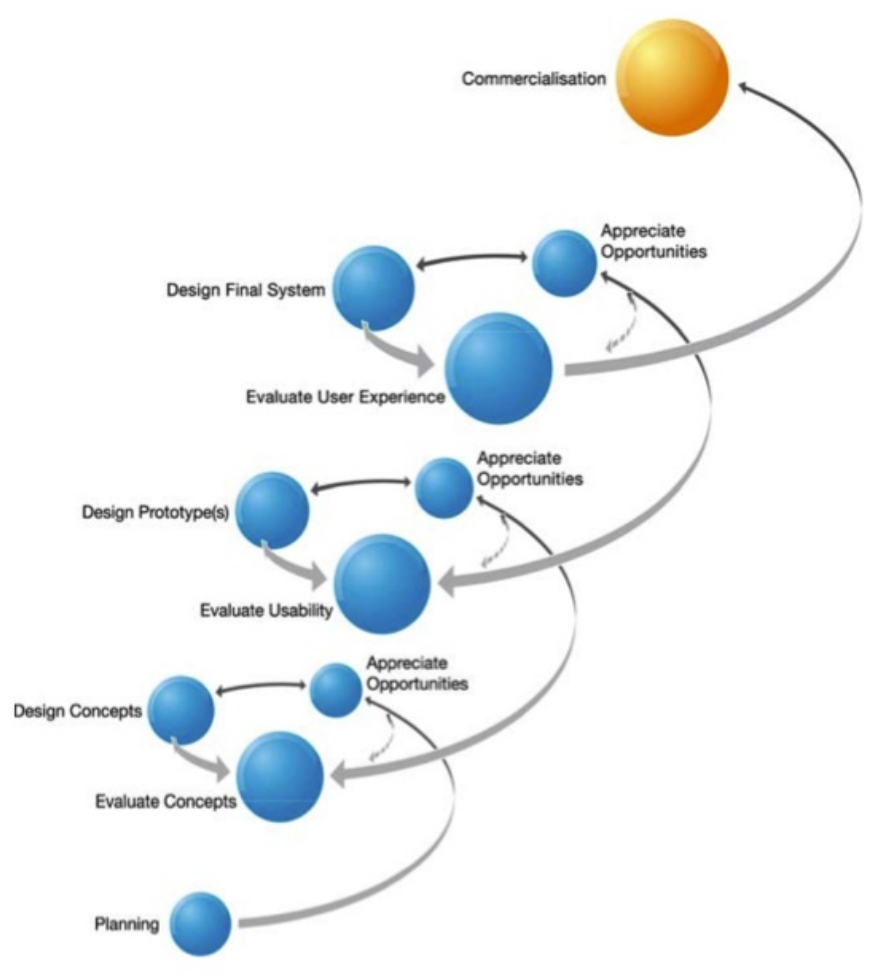

Figure 1. FormIT living labs methodology
The first phase (Design Concepts) is aimed at eliciting and prioritizing needs. Using rich narratives, users strive to find the best of "what is" and dream of "what could be". Interaction with users seeks to identify requisites and new possibilities while situated in real-life contexts. Based on the narratives developed, needs are categorized and prioritized, and initial concepts are formed. The second phase (Design Prototypes) is aimed at developing rough mock-ups and building on the results of the previous phase. The third phase (Design Final System) is aimed at concept valuation. In this phase, users test and evaluate in real-life contexts the prototypes developed in the previous phases. The iterative process often leads to changed or refined user needs with a focus on "what will be" and shaping the end product or service.

Within each stage, we can find a three-step process that begins with the appreciation of existing characteristics. Once these attributes are clearly established, the process continues with a collaborative design of concepts, prototypes and the final product/service. Real-life environment validation is maintained through the process as much as possible. This three-step process is repeated until the results are satisfactory.

\section{iLab.o}

iLab.o (ibbt.be/en/develop-test/ilab-0), in Belgium, has played an important role in the living labs community, reinforced by the presence of the Secretariat of the ENoLL in Flanders. iLab.o is the living lab division of the innovation research institute IBBT (ibbt.be/en), which was founded by the Flemish government. iLab.o provides a methodology for living lab initiatives while supplying services that facilitate their implementation.

iLab.o's methodology is based on the social construction of technology (SCOT; tinyurl.com/cgcyty) framework, which suggests that technology is shaped by the user and highlights the importance of context in the process of endowing technologies with social meanings. Users are considered the central focus and facts and meanings are the results of social processes (Sretenova, 2002: tinyurl.com/8qgmlo4; Tuomi, 2002: tinyurl.com/m73rb9).

iLab.o formalized its living lab methodology in 2005 (Pierson and Lievens, 2005; tinyurl.com/9t9sylo) and subsequently published experiences on concrete implementations of it (Ballon et al., 2005: tinyurl.com/8hox58r). The methodology consists of four phases aimed at understanding the context where the technology will be adopted and emphasizing the changes in meanings that this adoption will produce (Figure 2). 


\section{Mapping Living Labs in the Landscape of Innovation Methodologies}

Esteve Almirall, Melissa Lee, and Jonathan Wareham

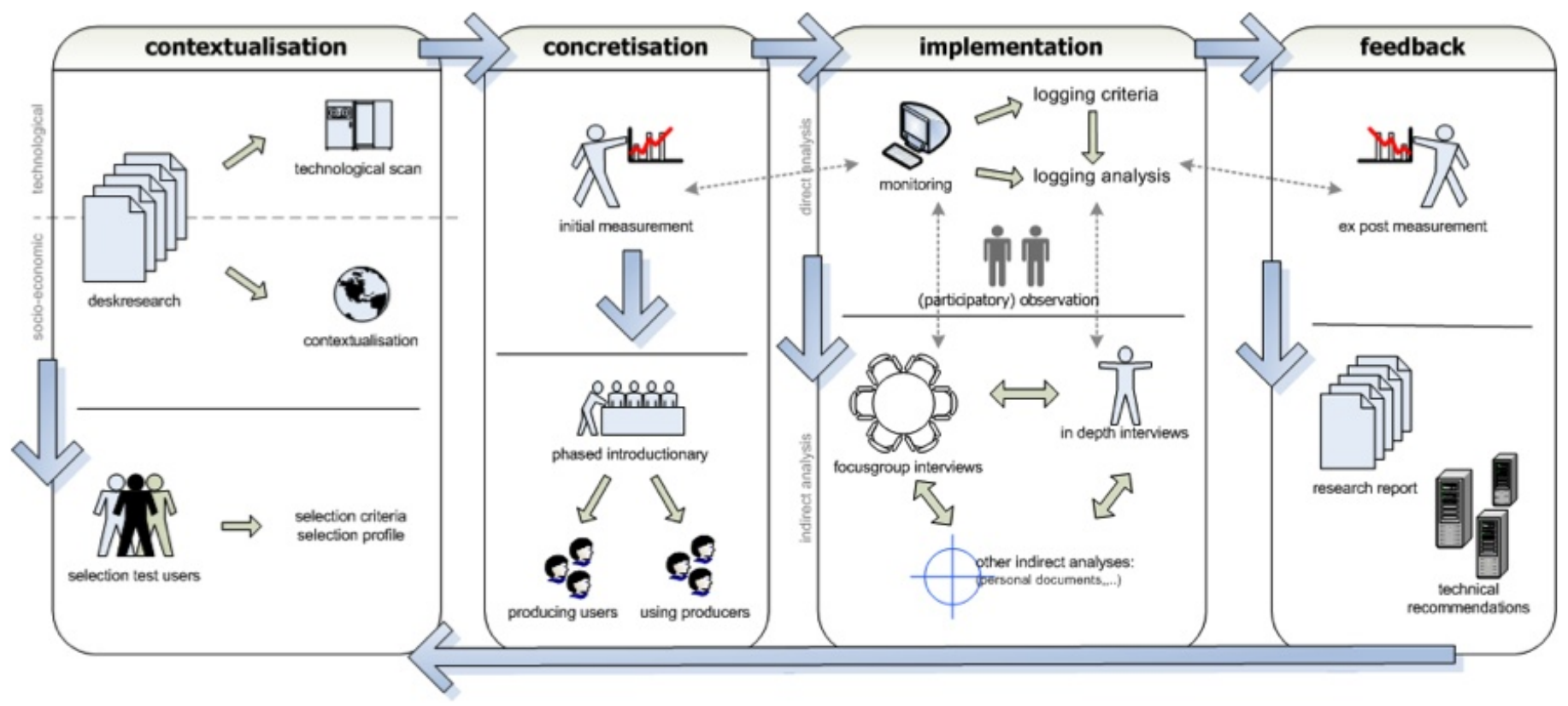

Figure 2. iLab.o living labs methodology

1. Contextualization. The contextualization phase aims to capture the relevant background information and insights around the subject of research. This information is then used to select a group of users for participation in the project.

2. Concretization. The key element of this phase is obtaining an initial, ex ante, snapshot of the user panel that can be later compared with one ex post measurement, after the introduction of the new technology or the innovation to be validated.

3. Implementation. The actual test and validation process is carried out in the implementation phase. Direct measurements are embedded in the device or in the platform and are implemented by means of logging, thereby reflecting patterns of use. Indirect measurements aim at capturing the meanings and context of use are carried out by a combination of ethnographic observation and qualitative analysis such as in-depth interviews or focus group exercises.

4. Feedback. Ex post measurement is conducted in this phase. The results are compared with those obtained in the contextualization and implementation phases and used to infer and produce recommendations on the concrete diffusion and implementation of the technology.
Helsinki Living Labs

Helsinki Living Labs (tinyurl.com/9dcov9n) was launched in 2007 to act as a connector between companies and the public sector interested in collaborating with living labs. The organization facilitates activities in Helsinki and surrounding cities, encompassing eight living labs, together with associated organizations of developers, enablers, and utilizers.

Helsinki living labs follows a three-phase methodology that evolves in a spiral (Figure 3). In the first phase (Grounding), stakeholders are identified and users from the community are selected. The second phase (Interactive and Iterative Co-Design) sees users explore the definition of concepts and work in the co-design of prototypes. Finally, in the third phase (Appropriation and Implementation), the final outcome is tested and feedback is gathered.

\section{Catalan Living Labs}

A living labs network was formed in Catalonia, Spain in 2006 to coordinate the different experiences and work of several research institutions using living labs methodologies. The majority of projects in Catalan are business to business. From Catalan Living Labs cases (Almirall and Wareham, 2008; tinyurl.com/8vwtjw2), we can infer a reliance on a three-phase methodology con- 


\section{Mapping Living Labs in the Landscape of Innovation Methodologies}

\section{Esteve Almirall, Melissa Lee, and Jonathan Wareham}

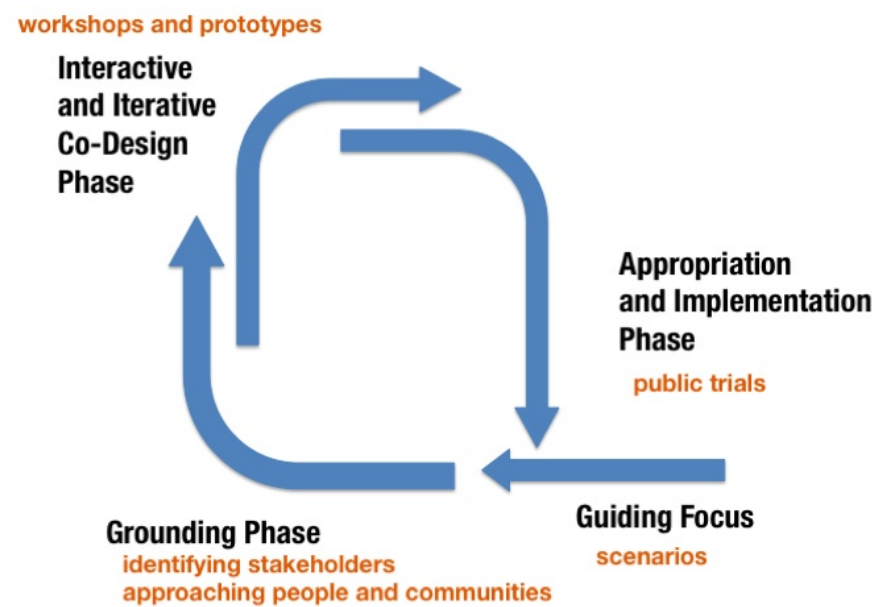

Figure 3. Helsinki Living Labs methodology

ducted in a spiral, but with an important shift in focus from needs-finding and context assessment towards implementations in real-life environments that serve not only as a proof of concept but as a starting point for a public or commercial venture (Figure 4).

The first phase of Catalan Living Labs is devoted to group selection. Great care is taken to involve the relevant set of users, not only because their insights could contribute to the development of a better product or service but also because they could help in creating a wave of momentum once it has been taken to market.

The second phase is devoted to the creation of an innovation arena. This is a distinctive characteristic of the Catalan model that supports the objective of reducing uncertainty and risk by demonstrating the solution's viability in real-life environments and by fostering early demand. This often involves the use of advanced infrastructure not generally available for public use. For example, the Catalan Living Labs network relies extensively on the use of Internet2 (high-speed Internet) research networks and state-of-the-art sensor networks for experimentation.

The final phase is devoted to context development and consists of experimentation in real-life environments, with an emphasis on developing business models that could make the project sustainable.

\section{Living Lab Methodology Contributions}

These four cases provide a description of some representative living lab methodologies that cover a wide spectrum of practices in the living labs community. Al-

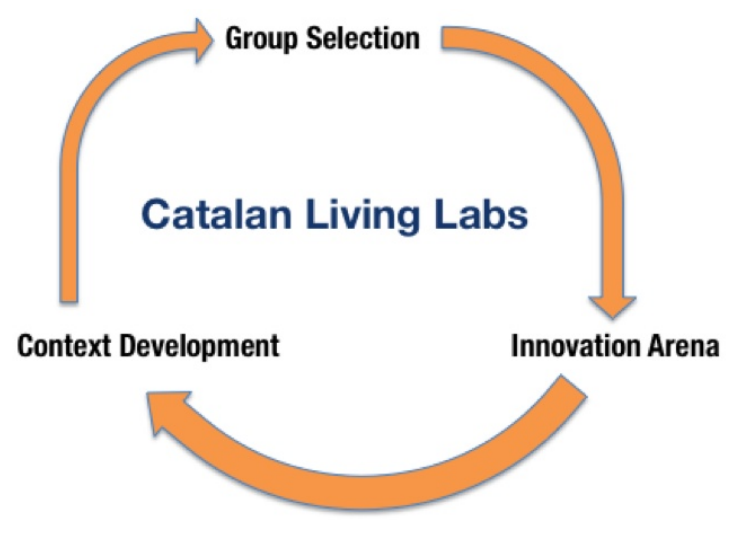

Figure 4. Catalan Living Labs methodology

though each one has its distinctive flavour, they share some common characteristics.

In all cases, we observe the engagement of users in the early stages of the innovation process. In the case of TestBed Botnia, this engagement has a well-defined objective: to collect user needs and engage them early in a co-design exercise. A similar approach can be found in the case of the Helsinki Living Labs, however a greater emphasis is placed on the selection of users. iLab.o shares the emphasis on selecting the "right" subset of users. Additionally, they emphasize involving a large number of participants so that the emergent solutions will ultimately be favoured by the target population of end users. And, in Catalan Living Labs, selection is focused on users that best express the relevant domain expertise, providing concrete insights when interacting with the solution implementation.

Therefore, in all cases, we can find clear initiative to involve users early on in the innovation process in order to capture either market knowledge about preferences, suitability of the implementation, or more specialized domain-based knowledge. Living labs methodologies aim to incorporate and evolve this knowledge in products and services through co-creation.

Proposition 1. Living lab methodologies engage a select group of users in the innovation process to capture market and domain-based knowledge and involve them iteratively through a co-creation process.

The most distinctive characteristic of living labs methodologies is the focus on real-life environments as the locus of research. Again, we find some differences in 


\section{Mapping Living Labs in the Landscape of Innovation Methodologies}

Esteve Almirall, Melissa Lee, and Jonathan Wareham

how various living labs seize the opportunities that this choice provides.

In TestBed Botnia and Helsinki Living Labs, proposals are derived from user needs and transposed to real-life situations, ranging from scenarios to the actual environment as research progresses. iLab.o places even more importance on the selection and appropriateness of the context in order to allow for the emergence of new uses and meanings. And, with their focus on capturing domain-based knowledge, Catalan Living Labs see context as important because the expertise that is often tacit becomes codified when applied to a certain environment.

Real-life contexts are therefore much more than a more realistic scenario for validating proposals; they form an arena where new meanings can emerge, tacit knowledge can be captured, and the whole ecosystem can be validated.

Proposition 2. Living labs elicit new understandings and meanings, and capture tacit and domainbased knowledge by situating and evolving innovation projects in real-life contexts and taking the opportunity to involve the whole ecosystem.

The third distinctive characteristic of living lab methodologies, especially when compared with close siblings such as participatory design, is the presence of publicprivate-partnerships.
In TestBed Botnia and iLab.o, institutional support is provided through policy measures that encourage public institutions to foster and develop initial demand for products and services coming out of living lab exercises. The Helsinki Living Labs offer a similar case in which there is public involvement in the trials of products and services, and if successful, their adoption is encouraged by public organizations. Catalan Living Labs goes even further by leveraging partnerships in the living lab to penetrate highly regulated and complex environments, such as the public health sector.

Proposition 3. Living labs take advantage of public-private partnerships for generating an initial demand and often involve other actors such as small and medium-sized entreprises to lower barriers of entry in complex multi-stakeholder or highly regulated environments.

Table 1 summarizes how living labs are differentiated on the basis of three main characteristics (Almirall and Wareham, 2008; tinyurl.com/8vwtjw2): user involvement, real-life contexts, and public-private partnership.

\section{Mapping User Involvement in Innovation}

Understanding living labs methodologies requires recognizing their unique contributions and positioning these practices in the landscape of other user-contributed methodologies for innovation (Figure 5).

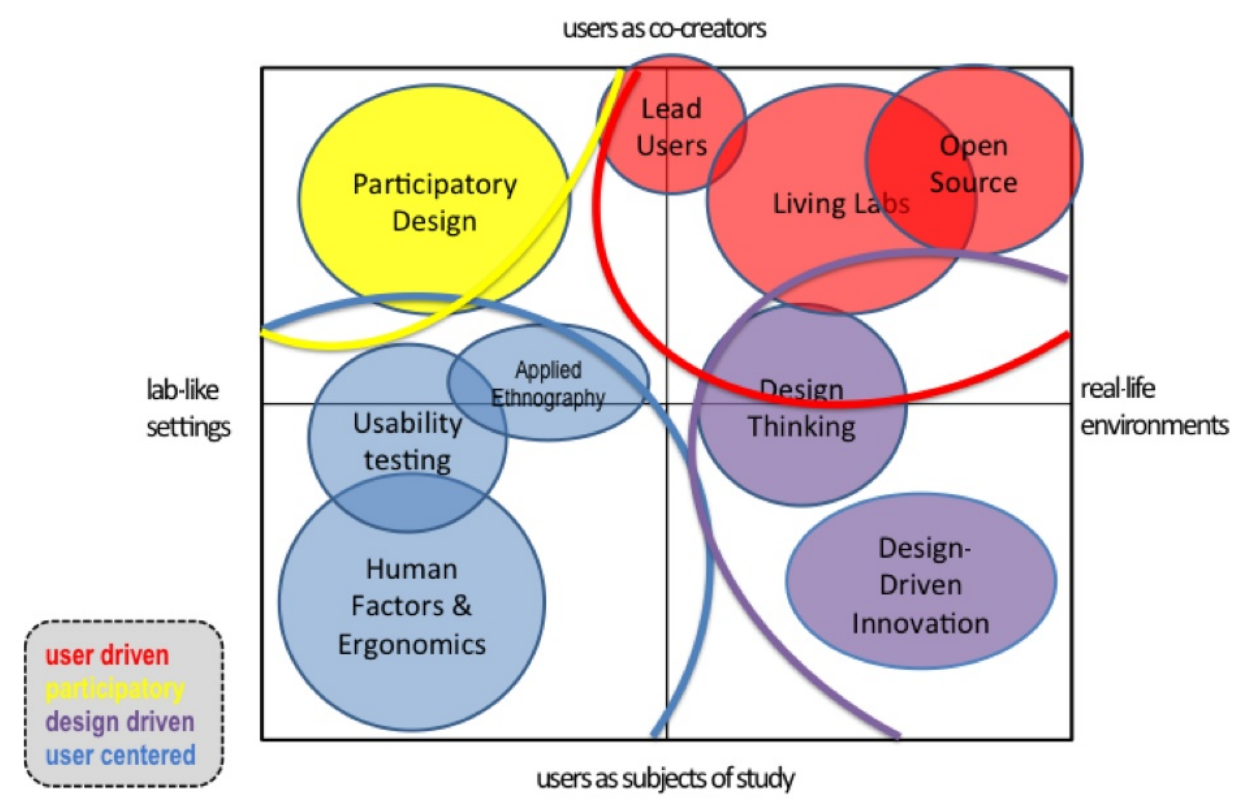

Figure 5. Mapping user-innovation methodologies 


\section{Mapping Living Labs in the Landscape of Innovation Methodologies}

\section{Esteve Almirall, Melissa Lee, and Jonathan Wareham}

The first dimension of interest is taken from the main characteristic of living labs: the involvement of users in a co-creative process. We can observe a diversity of practices along that dimension. On one end of the spectrum, users are regarded as subjects of observation, such as in human factors, ergonomics, or applied ethnography. On the other extreme, users are co-creators, such as in the case of lead users or open source communities. In the middle, we find the majority of methodologies, such as co-design, design thinking, and design-driven innovation.

The second dimension of interest speaks to a key aspect of living labs methodologies as well as other user-oriented innovation methodologies: whether the project is carried out in a lab-like environment or in the real-life settings in which users would typically conduct their activities.
Following the first axis - the level of user involvement in the innovation process - we divided methodologies in four different categories:

1. User centered. Users are mostly passive subjects of study. This is the case of usability testing, human factors, and applied ethnography.

2. Design driven. Designers take the lead. Design-driven methodologies normally work in real-life environments; however, they are led by designers who seek to find novel solutions.

3. Participatory. Users are considered on equal ground with the rest of the partners in a co-creative process. Participatory design, particularly the Scandinavian tradition, and generative design research belong to this category.

Table 1. Implementation of the main living lab characteristics in the four cases presented

\begin{tabular}{|c|c|c|c|}
\hline & User Involvement & Real-Life Contexts & Public-Private Partnership \\
\hline TestBed Botnia & $\begin{array}{l}\text { - capture of user needs } \\
\text { - co-design and participatory } \\
\text { design } \\
\text { - gathering domain and } \\
\text { market-based knowledge }\end{array}$ & $\begin{array}{l}\text { - locus for appreciation of } \\
\text { opportunities } \\
\text { - evaluation and validation of } \\
\text { prototypes }\end{array}$ & $\begin{array}{l}\text { - living lab is a public-private } \\
\text { partnership } \\
\text { - facilitates multi-stakeholder } \\
\text { involvement in projects }\end{array}$ \\
\hline iLab.o & $\begin{array}{l}\text { - contextualization of } \\
\text { prototypes for new } \\
\text { products and services } \\
\text { - selection of the "right } \\
\text { users" is a key element }\end{array}$ & $\begin{array}{l}\text { - focus on data gathering } \\
\text { - attempts to capture insights } \\
\text { from a large group of users }\end{array}$ & $\begin{array}{l}\text { - living lab is a public-private } \\
\text { partnership } \\
\text { - facilitates multi-stakeholder } \\
\text { involvement in projects }\end{array}$ \\
\hline Helsinki Living Labs & $\begin{array}{l}\text { - needs finding } \\
\text { - co-design and participatory } \\
\text { design }\end{array}$ & $\begin{array}{l}\text { - use of geographical context } \\
\text { for selecting users } \\
\text { - public, open trials } \\
\text { - validation of prototypes }\end{array}$ & $\begin{array}{l}\text { - living lab is a public-private } \\
\text { partnership } \\
\text { collaboration with town and } \\
\text { local authorities facilitates } \\
\text { trials and the uptake of new } \\
\text { products and services }\end{array}$ \\
\hline Catalan Living Labs & $\begin{array}{l}\text { - selection of "relevant users" } \\
\text { - fostering social } \\
\text { entrepreneurs and lead } \\
\text { users } \\
\text { - gathering of domain and } \\
\text { context-based knowledge }\end{array}$ & $\begin{array}{l}\text { - specialized contexts: } \\
\text { hospitals, opera theatres, } \\
\text { etc. } \\
\text { - large public trials together } \\
\text { with small specialized ones } \\
\text { - unexpected opportunities } \\
\text { because of the real-life } \\
\text { context }\end{array}$ & $\begin{array}{l}\text { - living lab is a public-private } \\
\text { partnership } \\
\text { - creation of initial demand, } \\
\text { especially in the public sector, } \\
\text { ensuring sustainability } \\
\text { - facilitates trials in public } \\
\text { contexts, very relevant in } \\
\text { highly regulated environments }\end{array}$ \\
\hline
\end{tabular}




\section{Mapping Living Labs in the Landscape of Innovation Methodologies}

\section{Esteve Almirall, Melissa Lee, and Jonathan Wareham}

4. User driven. Where the user is the one who drives the innovation process. Such is the case of open source, lead users and living labs.

The second dimension of interest refers to the locus of innovation. Traditionally, experiments have been carried out in laboratory-like settings that allow for more control and easier data gathering. However, more recent practices favour real-life environments in spite of the loss of control that they exhibit.

Determining the best context is largely based on the type of knowledge that living labs seek from users. On one hand, if the result of user participation is the capture of domain-based knowledge, then a closed group of selected users will work well. On the other hand, a real-life environment will be more beneficial if the aim is to capture market-based knowledge, forecasting the preferences of users towards a new solution that would benefit from multiple contributions and points of view.

\section{Conclusions}

The primary conclusion drawn from our investigation of living labs is that this methodology is a process of fit. That is, living labs will be an appropriate choice of innovation methodology where the fit of a particular technology or set of technologies to a precise context is more significant. Therefore, products and services that depend more on their soft characteristics for user acceptance and economic viability seem to be more appropriate.

The second conclusion is that living labs will be more relevant where the fit is unique to a given set of users. Indeed, if the fit is more trivial, it can possibly be inferred using other methodologies, perhaps from observing users without having to involve them. At any rate, in situations with multiple stakeholders, conflicting interests, and a large space of solutions, the innovation problem may only be adequately addressed by involving all constituencies and through their active participation. Living labs provide the solution by tapping into tacit knowledge to be incorporated into products and services, and validated in real-life environments.

\section{About the Authors}

Esteve Almirall is an Associate Professor in the ESADE Business School and Pompeu Fabra University in Barcelona, Spain. His research focuses on innovation and innovation management, and he has more than 30 publications in this field. His background is a mix of Management Science $(\mathrm{PhD})$ and Computer Science (MSc, MRes). Esteve is also highly involved in European Projects and EU organizations being a Council Member of the ENoLL (European Network of Living Labs) and coordinating/participating in EU projects on innovation and smart cities.

Melissa Lee is a PhD candidate at the ESADE Business School in Barcelona, Spain. Her research interests include open innovation, business ecosystems, and innovation in the public sector.

Jonathan Wareham is a Professor of Information Systems in the ESADE Business School in Barcelona, Spain. Dr. Wareham's research has been published, or is forthcoming, in over 80 refereed journals and proceedings. He currently serves as Vice-Dean of Research at ESADE and is Director of the ESADE Institute for Innovation and Knowledge Management. In addition, he sits on the advisory boards or editorial boards for a number of academic institutions, journals, NGOs, and social entreprises.

Citation: Almirall, E., M. Lee, and J. Wareham. 2012. Mapping Living Labs in the Landscape of Innovation Methodologies. Technology Innovation Management Review. September 2012: 12-18. 